\title{
A DESCONSTRUÇÃO DA POLÍTICA LINGUÍSTICA EDUCACIONAL: EM FOCO A IDENTIDADE DO PROFESSOR DE PORTUGUÊS ${ }^{1}$
}

\author{
DESCONSTRUCCIÓN EN LA POLÍTICA DE EDUCACIÓN LINGÜÍSTICA: \\ FOCUS SOBRE LA IDENTIDAD DEL PROFESOR DE PORTUGUÉS
}

\section{THE DECONSTRUCTION OF LANGUAGE EDUCATION POLICY FOCUS IDENTITY OF PORTUGUESE TEACHER}

Alex Pereira de ARAÚJO²

RESUMO: Utilizando a abordagem discursivo-desconstrutiva, este trabalho busca refletir sobre a política linguística nacional veiculada nos Parâmetros Curriculares Nacionais de Português (ensino fundamental) cujo discurso se traduz em um método sofisticado de controle e em uma forma eficaz de gerir a mudança (LAWN, 2001, p. 117). Nessa perspectiva, "todo sistema de educação é uma maneira política de manter ou de modificar a apropriação dos discursos, com os saberes e os poderes que eles trazem consigo" (FOUCAULT, 2008, p. 45). Através dessa abordagem, pretende-se apresentar e discutir os resultados analisados, cujo foco recai sobre as representações da (s) identidade (s) e competências construídas para os professores neste discurso, representações sociais da profissão do professor na sociedade contemporânea brasileira, marcada pelos acontecimentos que sucederam ao período ditatorial, portanto, a fase de redemocratização do país e de modernização do Estado frente às exigências da mundialização.

PALAVRAS-CHAVE: Discurso. Política linguística. Professor. Identidade.

RESUMEN: Utilizando el enfoque discursivo-deconstructivo, este trabajo busca reflexionar sobre la política lingüística nacional ofrecida a través de los Parámetros de Estudios Nacionales del Portugués (escuela primaria) cuyo discurso se traduce en un sofisticado método de control y una manera eficaz de gestionar el cambio (LAWN, 2001, p. 117). En esta perspectiva, "todo el sistema de educación es una forma política de mantener o modificar la apropiación del discurso, con el conocimiento y el poder que traen con ellos" (Foucault, 2008, p. 45). A través de este enfoque, tenemos la intención de presentar y discutir los resultados analizados, cuya atención se centra en las representaciones de las identidades y capacidades incorporadas para los profesores en este discurso, las representaciones sociales de la profesión docente en la sociedad brasileña contemporánea, marcada por acontecimientos que siguieron el período dictatorial, por lo tanto, la fase de democratización del país y la modernización del estado frente a las exigencias de la globalización.

PALAVRAS CLAVE: Discurso. Política lingüística. Maestro. Identidad.

${ }^{1}$ Projeto Traduzir Derrida Políticas e Desconstrução, CNPq

${ }^{2}$ Universidade Estadual do Sudoeste da Bahia, UESB

RIAEE - Revista Ibero-Americana de Estudos em Educação, v. 11, n. 3, p.1259-1280, 2016. 
ABSTRACT: Using the approach deconstructive discourse, this paper reflects on the national language policy conveyed in the Portuguese National Curriculum (primary school) - whose speech is translated into a sophisticated method of control and in an effective way to manage change (LAWN, 2001, p. 117), in order that "every system of education is a political way of maintaining or modifying the appropriation of discourses, with the knowledge and the powers they bring with them "(FOUCAULT, 2008, p.45).Through this approach, we intend to present and discuss the results analyzed, whose focus is on the representation $(s) I D(s)$ and competencies built for the teachers in this discourse, social representations of the profession of teacher in contemporary Brazilian society, marked by events that follow the dictatorial period, therefore, the country's democratization and modernization of the state before the demands of the globalized worlds.

KEYWORDS: Discourse. Language policy. Professor. Identity.

\section{Introdução}

A linguagem é tão natural a nós seres humanos - falantes/ouvintes (ideais ou reais); interlocutores/locutores; usuários; sujeitos (interpelados ou assujeitados) - que esquecemos que, como o coração, ela é indispensável para nossa vida ao possibilitar que os acontecimentos no mundo humano ocorram por seu intermédio. Noam Chomsky, linguista e ativista político norte-americano, chega a dizer que a linguagem é como um órgão do corpo, com seu sistema, com suas funções (internalizados na mente humana). Por outro lado, tal naturalidade naturalizada, muitas vezes, impede-nos de percebê-la como jogo que se joga com o outro na cena enunciativa em que a palavra ganha sentidos e poder. O perigo está quando a tratamos com naturalidade, corremos o risco de esquecer que "a linguagem é poder, talvez o primeiro poder do homem" (CHARAUDEAU, 2008, p. 7). E o poder só faz sentido no meio social, como prática social, uma vez que "o indivíduo não pode fugir à sua dependência da sociedade, mesmo quando age sozinho: o material, as habilidades, a própria linguagem, de que utiliza, são produtos sociais" (SARUP, 1986, p. 123).

Por isso, não há um só evento no mundo dos homens em que ela não esteja presente e envolvida com o poder, cujo uso é, dentre outras coisas, para dominar o outro, seja pela argumentação, seja pelo poder de transmitir e produzir informações, tomando ou (im) pondo a palavra. Em meio a estes eventos e jogos, nós nos deparamos com a questão da identidade, ou melhor, do seu processo de construção, o qual se efetiva por meio de uma política de representação (RAJAGOPALAN, 2001, p. 75), 
sobretudo, da identidade de profissões ligadas diretamente com a manipulação do poder, como é o caso da identidade dos professores cujos efeitos de sentidos ecoam nos discursos veiculados na escola (CORACINI, 2003a, 2003b, 2007).

Nesse sentido, Lawn (2001, p. 117) observa que "as tentativas do Estado para criar novos tipos de professores para novas orientações da política educativa, originadas em diferentes períodos deste século $(\mathrm{XX})$, têm sido as principais formas pelas quais a identidade dos professores tem sido construída e mantida" por meio do discurso oficial. Para Foucault (2008, p. 45) "todo sistema de educação é uma maneira política de manter ou de modificar a apropriação dos discursos, com os saberes e os poderes que eles trazem consigo" em que "a própria rede institucional desenha uma rede de difusão, as características de um público, indissociáveis do estatuto semântico que o discurso se atribui" (MAINGUENEAU, 2007). E nessa rede do jogo discursivo, como prática, que entra em jogo a identidade pela qual tal política de representação, de que fala Rajagopalan (2001), passa. São práticas frequentemente mal conhecidas, pouco estudadas, ou que, quando o são, nunca são postas em relação com o dito dos discursos concernidos.

Nosso grande desafio aqui será justamente (re)pensar a identidade dentro de uma política de representação num momento de intensas e tensas transformações, ou melhor, de questionar a eficácia dessa política dentro dos eventos contemporâneos, principalmente, no universo da democracia brasileira em fase de consolidação. Para isso, utilizaremos a abordagem discursivo-desconstrutiva, buscando refletir acerca da política linguística nacional veiculada nos Parâmetros Curriculares Nacionais de Português (ensino fundamental, doravante PCN2-EF2) cujo discurso se traduz em um método sofisticado de controle e em uma forma eficaz de gerir a mudança (LAWN, 2001, p.117). Nesse sentido, o professor, como receptor desse discurso, está na posição daquele "habilitado" a por em práticas as novas demandas educacionais do governo, o qual se utiliza do discurso dos especialistas para se valer dos saberes e poderes da ciência para disseminar uma nova identidade linguística para o professor de português.

Para nossa análise, nós tomamos como Coracini (2003a, p. 193) a noção de discurso como dispersão e a noção de sujeito heterogêneo, possuído pelo inconsciente e pelo desejo do outro. Pensamos, antes com Charaudeau (2006), que “é necessário interrogar-se sobre a natureza e o funcionamento do que chamaremos, por ora, de palavra política, na medida em que ela se inscrever em uma prática social, circulada em certo espaço público e tem qualquer coisa que ver com as relações de poder que aí se 
instauram" (p. 16) para entendermos que o ensino de língua primeira (L1) se constitui a partir de uma política linguística ao instaurar uma política de planejamento linguístico, no sentido dado a esse termo por Calvet (2007).

Ninguém há de negar que as articulações simbólicas e linguísticas são criadas e gerenciadas pelo Estado por motivos políticos. Por isso, segundo Payer (2005, p. 13 apud DINIS, 2007, 364), “os modos de ser sujeito ao longo da história social não se apresentam sempre idênticos", ou seja, na Idade Média, a sociedade se organizava a partir das leis divinas, sendo a divisão social entre senhor, nobre e súdito legitimados pela igreja; com a Revolução Francesa, o poder da organização social passa a ser administrado pelo Estado Nacional, o qual se constitui como uma "meta-instituição doadora de sentido”. De Lá para cá, isso pouco mudou. Por esses motivos, Silva (2008), afirma que "o poder de definir a identidade e de marcar a diferença não pode ser separado das relações mais amplas de poder". De onde vem o sentimento de pertencimento e de identidade linguística senão de políticas linguísticas que os constroem e os propagam?

Tentaremos desnaturalizar a construção de identidade por meio da análise discursivo-desconstrutiva, cujo foco recai sobre as representações da (s) identidade(s) e competências construídas para os professores no discurso (veiculado nos PCN2-EF2), representações sociais da profissão do professor na sociedade contemporânea brasileira, marcada pelos acontecimentos que sucederam ao período ditatorial, portanto, a fase de redemocratização do país e de modernização do Estado frente às exigências da mundialização.

\section{A desconstrução do discurso e de identidade}

As identidades estão sempre sendo reconstruídas em políticas de representação como é o caso das políticas linguísticas. Para Rajagopalan (2001, p. 71), a única maneira de definir uma identidade é em oposição a outras identidades em jogo. No discurso em análise, a identidade do professor do Brasil democrático se opõe aquela do período dos anos de chumbo (1964-1984), quando predominou a tecnologia educacional, sustentada pelo projeto de "modernização e desenvolvimento nacional" imposto à nação pelo regime militar (Geraldi, 1996, p. 71).

Essa prática de (re)construir identidade linguística está na gênese da nossa história desde a política pombalina. Magda Soares (1996), em Português na escola: 
história de uma disciplina curricular, faz um estudo apresentando uma importante perspectiva histórica para compreender o estatuto atual não só da disciplina, mas também dos principais sujeitos envolvidos no processo educacional, ou seja, professores e alunos (de forma indireta).

Podemos perceber que estas políticas sempre partem de uma necessidade aparentemente nova ou apresentada como tal. Segundo Nietzsche (1987, p. 31), "a maior parte das necessidades é construída e carrega interesses que advêm da vontade de potência e da vontade de verdade", construções que servem como sentido de ser para as políticas de representações, veiculadoras de identidades.

\section{O estatuto de enunciador e do destinatário (questões pragmáticas ou políticas?)}

Ao tomar como axioma "a língua é um fato social", nossa análise se apoia na relação interlocutiva de sujeitos no/do discurso porque pensar a linguagem como prática social é de certa forma pensar na perspectiva pragmática e, em se tratando de uma análise discursivo-desconstrutiva, somos obrigados a envolvê-la na análise quando tratamos de condições de produção do discurso, de efeitos discursivos, de sujeitos, de instituições e das práticas discursivas, da palavra tomada etc. Dito de outra forma, a pragmática aborda a linguagem como fenômeno simultaneamente discursivo, comunicativo e social (JACQUES apud ARMENGAUD, 2006, p. 11) num jogo cujo poder da palavra é o poder de mobilizar a autoridade acumulada pelo falante [jogador] e concentrá-la num ato linguístico (BOURDIEU, 2005).

De acordo com Maingueneau (2007, p. 91), "os diversos modos da subjetividade enunciativa dependem igualmente da competência discursiva, sendo que cada discurso define o estatuto que o enunciador deve conferir a seu destinatário para legitimar seu dizer". No caso do discurso em análise, propõe-se um destinatário "determinado" pelo enunciador à medida que esse não é, entretanto, um destinatário abstrato, um homem 'em si', como nos lembra Voloshinov (1976 apud ORLANDI, 2003, p.153). Mas o fato em questão é que tal discurso não questiona quem está habilitado a cumprir a ordem nele prescrita, colocando dessa forma o destinatário na posição daquele que deve obedecer, por isso dizemos que ele tem a força da lei, da ordem jurídica. Conforme Maingueneau (1997, p. 30), a referência à ordem jurídica opera-se então naturalmente, acionando com isso convenções que regulam institucionalmente as relações entre sujeitos. E isso vale para o discurso escrito, i.e., 
"por mais escrito que seja, tem uma voz própria, mesmo quando ele a nega" (MAINGUENEAU, ibidem).

Muitos autores questionam a falta de um movimento que possibilitasse a instauração de um diálogo nacional quando da elaboração dos PCN. Nesse sentido, Suassuna (1998, p. 178), afirma que "a unilateralidade da proposição do MEC pode ser explicada pelo próprio conteúdo das ações do governo federal em geral: num contexto político nacional e internacional marcado pela padronização, quase não há espaço para a percepção, a problematização e o enfrentamento das diferenças e divergência”. O fato constatado é uma questão para se refletir.

Esta unilateralidade na proposição do documento pode implicar em desvantagens na recepção do documento pelos professores? Se tivermos uma resposta afirmativa, então, os PCN são uma sugestão que "suavizam o tom (im) positivo e autoritário da ordem, da obrigação, de imposição"? Uma outra reflexão nos leva a questão: qual a força que tais documentos adquirem no ambiente escolar, sobretudo, nos discursos do professor? Há espaço de escolha neles? Para Souza (2003, p. 344), “o professor não tem lugar na elaboração dos parâmetros, já que essa tarefa coube a especialista. Daí a angustia do professor que, ao ler os documentos, não consegue dar um sentido àquele texto, pois trata-se de um discurso acadêmico, ao qual ele geralmente não tem acesso".

Coracini (2003) nos traz à baila outro questionamento, através de Lyotard, que retomamos aqui para ampliar nossa discussão: "como ser independente se vivemos numa sociedade em que [...] 'o acesso às informações é e será da alçada do experts de todos os tipos. [Em que] a classe dirigente é e será a dos decisores. [Em que] Ela já não é mais constituída pela classe política tradicional, mas por uma camada formada por dirigentes de empresas, altos funcionários, dirigentes de grandes órgão profissionais, sindicais, políticos, confessionais?"” (LYOTARD, 1979/1988, p. 27 apud CORACINI, ibidem).

Falando sobre a identidade no mundo contemporâneo pelo prisma dos estudos culturais, Woodward (2008, p.21), observa que

A homogeneidade cultural promovida pelo mercado global pode levar a uma resistência que pode levar ao distanciamento da identidade relativamente à comunidade e à cultura local. De forma alternativa, pode levar a uma resistência que pode fortalecer e reafirmar algumas identidades nacionais e locais ou levar ao surgimento de novas posições de identidades. 
Isso significa dizer que a homogeneização cultural e a imposição de novas identidades não ocorrem sem resistências, ainda que silenciosas, elas ocorrem e os conflitos fazem parte do universo da linguagem. Por meio dela, nós nos filiamos a redes de sentidos, nos identificamos com processos de significação e nos constituímos como posições de sujeitos, uma vez que "a língua comporta, a título irredutível, um catálogo completo de relações inter-humanas, toda uma coleção de papéis que o locutor pode escolher para si impor ao destinatário" (DUCROT, 1973 apud MAIGUENEAU, 1997, p. 30-31).

\section{O funcionamento do discurso e a construção da necessidade}

Os discursos ganham corpo e sentido dentro das instituições a que eles estão ligados direta ou indiretamente, ou melhor, vão sendo difundidos em práticas discursivas dentro delas. Para Maingueneau (2007, p. 125), “essa imbricação de um discurso e de uma instituição é aliás uma ideia que tem tendência a prevalecer cada vez mais."

Nesta perspectiva, o discurso aqui em análise pode ser definido como oficial na medida em que representa a instituição governo, mesmo que ele contenha em si o discurso de especialistas da ciência para construir a necessidade que exige uma nova identidade para o professor de Português em atuação na escola básica brasileira.

Lembremos que a abordagem que este documento apresenta em uma nova política linguística para o Brasil (ensino de L1 nas escolas) não é nova. De acordo com Geraldi (1996, p. 71), “os anos 80 inauguraram, no que concerne ao ensino de língua materna, duas preocupações distintas no meio acadêmico", o problema do baixo desempenho linguísticos dos nossos alunos e o desejo de resolução disso com a elaboração de propostas de ensino mais eficientes. Parece-nos claro que o governo se apropriou delas, traduzindo-as em necessidades para, em seguida, oficializá-las como uma "nova prática oficial", bem como para mostrar aos organismos internacionais a implementação de uma nova política, exigência do mercado global através desses organismos.

Dito isso, podemos constatar, inicialmente, o sentido de ser da "necessidade" nos excertos extraídos dos PCN2-EF2, em que analisamos as categorias de paráfrases e de sequências discursivas de referência (sdr, doravante), usadas por Courtine (1981), 
que as definem como sequências discursivas de um corpus em questão, escolhidas pelo analista para investigar as relações intra e interdiscursivas de um certo discurso, tomado como objeto. Podemos dizer, dessa forma, que estas sdr funcionam como elos discursivos para instaurar uma rede no/do discurso em retomadas. Vejamos:

(1) Os Parâmetros Curriculares Nacionais foram elaborados procurando, de um lado, respeitar diversidades regionais, culturais, políticas existentes no país e, de outro, considerar a necessidade de construir referências nacionais comuns ao processo educativo em todas as regiões brasileiras (Brasil, 1998).

No excerto (1), extraído dos PCN2-EF2, a necessidade apresentada como justificativa para a elaboração do documento é: "construir referências nacionais". Esta necessidade, traduz-se aqui como uma sdr (a sdr 1), a qual será retomada, como podemos ver, nos próximos excertos:

(2) A discussão acerca da necessidade de reorganização do ensino fundamental no Brasil é relativamente antiga, estando intrinsecamente associada ao processo de universalização da educação básica que se impôs como necessidade política para as nações do Terceiro Mundo a partir da metade do século XX. (gripo nosso)

(3) A nova realidade social, conseqüente da industrialização e da urbanização crescentes, da enorme ampliação da utilização da escrita, da expansão dos meios de comunicação eletrônicos e da incorporação de contingentes cada vez maiores de alunos pela escola regular colocou novas demandas e necessidades, tornando anacrônicos os métodos e conteúdos tradicionais. (grifo nosso)

(4) Os índices brasileiros de evasão e de repetência - inaceitáveis mesmo em países muito mais pobres - são a prova cabal do fracasso escolar. (BRASIL, 1998, p. 17).

Em (4), a forma da sdr1 como paráfrase é ø, i.e., em seu lugar aparece dados concretos que sugere uma retomada dela.

\section{Pondo em ordem a cidadania na democracia (os aspectos políticos)}

Nos PCN2-EF2 a palavra de ordem é cidadania. De acordo com Gilbert (1994, p. 30), "os usos educacionais da ideia de cidadania têm contado uma história diferente, enfatizando a ascensão progressiva de instituições democráticas baseadas em aceitação racional da relação contratual entre indivíduo e a nação". Nessa perspectiva, essa versão atualizada da narrativa da cidadania tem sido identificada em muitas pesquisas acerca da política educacional e de currículo como nos mostra Gilbert através dos autores Tapper e Salter (1978); Gilbert (1984); Ahier (1988) e Heater (1990). Dessa forma, afirma Gilbert (ibidem) que ela é ainda um argumento poderoso nas tentativas de se promover a 
educação voltada para a cidadania. A partir dessa discussão, poderemos compreender melhor sobre a identidade (im)posta nos documentos que constituem nosso corpus. Vejamos os excertos seguintes:

(5) (...) um projeto educativo comprometido com a democratização social e cultural atribui à escola a função e a responsabilidade de contribuir para garantir a todos os alunos o acesso aos saberes lingüísticos necessários para o exercício da cidadania (idem, p.19 [grifo nosso]).

(6) Toda educação comprometida com o exercício da cidadania precisa criar condições para que o aluno possa desenvolver sua competência discursiva" (idem, p. 23[grifo nosso]).

(7) Muito do fracasso dos objetivos relacionados à formação de leitores e usuários competentes da escrita é atribuído à omissão da escola e da sociedade diante de questão tão sensível à cidadania. (p.32)

(8) No processo de ensino-aprendizagem dos diferentes ciclos do ensino fundamental, espera-se que o aluno amplie o domínio ativo do discurso nas diversas situações comunicativas, sobretudo nas instâncias públicas de uso da linguagem, de modo a possibilitar sua inserção efetiva no mundo da escrita, ampliando suas possibilidades de participação social no exercício da cidadania (idem.)

Tomemos (5) como a sdr2 cuja repetibilidade parafrástica se dá em (6), (7) e (8). Qual o efeito de sentidos disso? Coracini (2007) realizou um estudo cuja motivação se deu pela frequência alusiva de "formar cidadania" nas redações de professores como objetivo pedagógico; segundo a autora, tal alusão aponta para um discurso atual sobre cidadania, recorrente no discurso político educacional, ou como falamos anteriormente, por meio de práticas discursivas difundidas no ambiente escolar. No entanto, do ponto de vista do funcionamento discursivo, Maingueneau (2007, p. 125), nos lembra que "a passagem de um discurso a outro é acompanhada de uma mudança na estrutura e no funcionamento dos grupos que gerem esses discursos". Dessa forma, a frequência alusiva da expressão "formar cidadão", constada por Coracini seria um indício das "práticas discursivas do governo que ganham corpo em esquemas de comportamento, nas suas formas pedagógicas, que simultaneamente as impõem e as mantêm (FOUCAULT, 1997, p.12).

$\mathrm{Na}$ análise das redações dos professores, podemos observar, pelo olhar da pesquisadora, que não é à toa que, a todo o momento, emerge, nesses discursos - de 
forma ora mais explícita, ora menos -, a questão da cidadania, como um pacote fechado, fetichizado, reificado onde apenas se vislumbram alguns ingredientes: criticidade, democracia, liberdade, criatividade..., norteadores de uma prática didática que também se apresenta como fetiche, pacote fechado, que se quer transformador e criador, silenciando as vozes sociais que questionam e desvalorizam a escola e o professor. Parece que o arremate dado por Coracini responde em parte algumas das questões que pensamos anteriormente.

Para ela, "todos esses efeitos de sentido de um discurso que se apresenta vazio e pleno ao mesmo tempo encontram sua justificativa no discurso político-educacional, aqui representado pelos Parâmetros Curriculares Nacionais (PCNs)" (CORACINI, ibidem, p. 103). A autora também faz uma rápida descrição desse discurso políticoeducacional como tendo

\begin{abstract}
o tom assertivo e informativo (manifestado pelo uso dos verbos no indicativo do presente ou futuro, pelo uso de orações completas com sujeito, verbo e complemento -, estrutura fechada que controla, ainda que ilusoriamente, o sentido) produz o efeito de verdade inquestionável, objetiva e definitiva, silenciando ou apagando que impera na sociedade brasileira(...) (ibidem).
\end{abstract}

\title{
Pondo em ordem a língua e os sujeitos em seus lugares (aspectos pedagógicos e linguísticos da política linguística)
}

Na rede discursiva tecida nos PCN2-EF2, a noção de "língua(gem)" aparece como a ponta do fio (conceito-chave) que estabelece uma relação direta com as palavras democracia, cidadania, autonomia, competência, inclusão, mediação, participação. Essa relação cria a ilusão de que a língua dos PCN2-EF2 não é uma construção idealizada de língua, de uma língua por-vir cujo desejo é dotar o sujeito de uma competência linguística que garanta o uso eficaz da linguagem, tornando-o cidadão num país que precisar vencer o problema da desigualdade social, ou seja, o domino da linguagem pode contribuir para diminuir tal desigualdade. Com isso, cria-se a ilusão de que a apropriação dessa língua pelo sujeito-professor, que deve oferecer ao sujeitoaluno, irá contribuir para o exercício da cidadania ao promover a igualdade social pelo uso social parametrizado da língua(gem). O conceito de língua trazido à tona pelos PCN2-EF2 é “a língua é um sistema de signos específico, histórico e social, que 
possibilita a homens e mulheres significar o mundo e a realidade" (BRASIL, 1998, p. 22) (grifo nosso). Tal conceito, ao conceber os signos linguísticos como históricos e sociais, busca se filiar a correntes linguísticas de inspiração bakhtiniana e, ao mesmo tempo, permitir a relação com as palavras do campo do universo da semântica política.

A língua concebida dessa forma, ganha um lugar de destaque porque pode promover a igualdade entre os sujeitos, os quais nas relações com a palavra precisam negociar os sentidos entre si, e isso só é possível se houver uma relação dialógica, em que os sujeitos precisam estar em posição de igualdade. Tal igualdade linguística parece ser o motivo para se pensar no exercício da cidadania como ação imbricada com os atos da língua (gem). Para Signorini (2008, p. 172), em políticas de Estados republicanos e liberais,

\begin{abstract}
essa igualdade é algo a ser conquistado individualmente por cada falante por meio do letramento escolar: por meio da escolarização, todos podem apropriar-se das formas e funções valorizadas pelo Estado e demais instituições e, assim, conquistar a igualdade de condições na comunicação social. Mas como esse é um objetivo sempre postergado para a maioria, inclusive os escolarizados, acaba funcionando como uma espécie de álibi que vai sempre justificar a diferença congênita irredutível que desqualifica a maioria dos falantes enquanto falantes autorizados e, consequentemente, enquanto interlocutores, agentes, cidadão etc.
\end{abstract}

Nesse sentido, sobre a doutrina da igualdade liberal, falava Nietzsche (2006, p. 98),

A doutrina da igualdade!...Mas não há veneno mais venenoso: pois ela parece ser pregação da própria justiça... "Igualdade aos iguais, desigualdade aos desiguais" - isto seria o verdadeiro discurso da justiça: e, o que daí se segue: "Nunca tornar igual o desigual".

Seria a igualdade apenas um efeito de linguagem usado pelo Estado? Há igualdade nas relações entre os sujeitos do PCN2-EF2? O documento apresenta o sujeito-aluno e o sujeito-professor como variáveis do ensino-aprendizagem ao lado do conhecimento linguístico a partir da noção de língua vista anteriormente. Cada um com seu papel e função no processo do ensino-aprendizagem em L1 na escola. Mas papéis e posições diferentes que formam um sistema hierárquico. Efeitos do falogocentrismo $?^{3}$ É

\footnotetext{
${ }^{3}$ Termo criado por Jacques Derrida, a partir de falocentrismo e logocentrismo, para designar o primado
} concedido de um lado pela filosofia ocidental ao logos platônico e, de outro, pela psicanálise à simbólica 
possível pensar em igualdade na democracia em uma relação como essa? Se "democracia significa, minimamente, igualdade"; qual o sentido dela dentro do ambiente escolar? Qual o lugar dos sujeitos nesse discurso produzido na democracia para fomentar cidadania a partir de ações no/do ambiente escolar? Vejamos como o documento define isto, ou melhor, a posição e função dos sujeitos e do "objeto" no excerto seguinte:

(9) (...) o aluno - é o sujeito da ação de aprender, aquele que age com e sobre o objeto de conhecimento. O segundo elemento - o objeto do conhecimento - são os conhecimentos discursivo-textuais e linguísticos implicados nas práticas sociais da linguagem. O terceiro elemento da tríade é a prática educacional do professor e da escola que organiza a mediação entre sujeito e objeto do conhecimento (BRASIL, op. cit., p. 22).

Aí fica claro qual é o lugar de cada um na escola, isto é, nessa relação fica claro quem tem o poder para organizar e mediar. Dito de outra forma, no espaço escolar, "o professor é institucional e idealmente aquele que possui o saber e está na escola para ensinar, o aluno é aquele que não sabe e está na escola para aprender" (ORLANDI, 2003, p. 31). Do mesmo modo, o discurso do documento se impõe como discurso dos especialistas convidados pelo MEC. O poder do especialista é o poder investido pelo poder político que o confere e reconhece como tal nessa relação de assujeitamento. Há aí uma quebra de leis discursivas, como nos ensina Ducrot (1979 apud ORLANDI, ibidem, p. 17). A motivação, o interesse, a informação é a força, a força de lei que o impõe como discurso legítimo para a escola e seus sujeitos. Daí a angustia do professor quando tenta ler o documento e encontra uma série de dificuldades em razão da falta de diálogo com os técnicos especialistas do governo, como constata Souza (2003, p. 344). Nessa relação de poder, caracterizada pela imposição de que manda, pode acabar transformando a reflexão em um automatismo, "porque na realidade, saber o material didático é saber manipular" (ORLANDI, op. cit., p. 22). Para exemplificar, vejamos os seguintes enunciados de tal discurso:

(10) $O$ objeto de ensino e, portanto, de aprendizagem é o conhecimento linguístico e discursivo com o qual o sujeito opera ao participar das práticas sociais mediadas pela linguagem (p.22) [grifo nosso].

Paremos um pouco para sentir a força do enunciado (10). Vejam só quão forte é a força estanque para com a reversibilidade e como é contido o seu potencial polissêmico! O tom assertivo e, ao mesmo tempo "informativo", produz um efeito de 
verdade, como nos lembra Coracini (op.cit., p. 103), postulando, dessa forma, uma abordagem diferente da anterior cuja ênfase na gramática era a base do ensino de L1. Ele não pressupõe, mas exige um professor que detenha habilidade e competência linguísticas para cumprir com seu dever de agente da cidadania. Como força de lei, o professor é obrigado a conhecer as terminologias da ciência da linguagem contidas no documento e a posição de linguistas que desautorizam a antiga prática, uma vez que para muitos, ela é totalmente antidemocrática porque prescreve o que dizer, o que pensar ao educando; ou, no dizer de Gnerre (1994, p.26), "é um resto de épocas em que as organizações dos Estados eram explicitamente ou declaradamente autoritárias e centralizadas". Dito de outra forma, tal diferença traz em si o peso dos argumentos da ciência como "verdades" cujo efeito é o tom assertivo e absoluto. Enunciado de um discurso pensado para a escola, para regulamentar as funções e o lugar dos sujeitos. Nesse sentido, Orlandi(op.cit.,) diz que "a escola se institui por regulamentos, por máximas que aparecem como válidas para ação, como modelos" (p. 28). Por outro lado exige de quem ensina uma visão de que o ato de ensinar deve ser pensado como algo "consciente" e eminentemente necessário para superar a crise no ensino de português e para promover o exercício da cidadania.

No excerto (11) abaixo, além de apresentar a necessidade de um profissional que saiba gerenciar as atividades de sala de aula e do contexto escolar, reforça a ideia de que o professor precisa de habilidade e competência linguísticas para desempenhar "o papel de informante e de interlocutor privilegiado", como vemos a seguir:

(11) "Ao professor cabe planejar, implementar e dirigir as atividades didáticas, com o objetivo de desencadear, apoiar e orientar o esforço de ação e reflexão do aluno, procurando garantir aprendizagem efetiva. Cabe também assumir o papel de informante e de interlocutor privilegiado, que tematiza aspectos prioritários em função das necessidades dos alunos e de suas possibilidades de aprendizagem" (ibidem).[grifo é nosso]

No enunciado (12), demonstra a necessidade de um profissional "criador de condições" para que os alunos possam, mediante o desenvolvimento discursivo, exercer a cidadania.

(12) Toda educação comprometida com o exercício da cidadania precisa criar condições para que o aluno possa desenvolver sua competência discursiva. (p.23). 
Já no enunciado (14), aparece claramente a exigência de um profissional "mediador".

(13) "Nas situações de ensino de língua, a mediação do professor é fundamental". (BRASIL, ibidem, 47);

E por fim o enunciado (14) ele restringe o poder atribuído ao professor no enunciado (11), mas reforça a ideia de gerenciador de conteúdos.

(14) "Os conteúdos que serão apresentados para o ensino fundamental no terceiro $e$ no quarto ciclo são aqueles considerados como relevantes para a constituição da proficiência discursiva e lingüística do aluno em função tanto dos objetivos específicos colocados para os ciclos em questão quanto dos objetivos gerais apresentados para o ensino fundamental, aos quais aqueles se articulam." (BRASIL, 52).

A análise dos enunciados, nesta abordagem discursivo-desconstrutiva, aponta para as seguintes características da identidade fabricada para o professor pela política linguística (e/ou educacional) materializada nos PCN2-EF2:

a) O professor como criador de condições para cidadania

b) O professor mediador

c) O professor como aquele que detém a habilidade e competência linguísticas

e) O professor como gerenciador de conteúdos e recursos didáticos.

Comparando-as com o estudo de Lawn (2001, p.128), embora se trate do discurso oficial da educação na Inglaterra, podemos verificar algumas semelhanças com o caso brasileiro. Neste estudo, o autor mostra que para tornar possível a gestão do seu trabalho, os professores serão regulados no contexto de um discurso que acentua a ideia do desempenho, individualização e liderança. Assim, o professor deverá ter as seguintes competências:

- Esperar sucesso, por parte dos alunos;

- Assumir responsabilidade pessoal pelo seu próprio desenvolvimento no trabalho e avaliar a sua própria prática (em comparação com os outros);

- Trabalhar sob forte liderança;

- Estabelecer redes com outros professores e trabalhar com os pais e empresas. (ibidem). 
Já na pesquisa realizada por Coelho (2009, p. 5), analisa se os sentidos da formação e da construção de identidade de professores nos projetos institucionais: Proformação, Veredas e a Rede Nacional de Formação Continuada de Professores de Educação Básica. Aí, autora encontrou nos fundamentos do Projeto Veredas, uma identidade caracterizada por três dimensões inseparáveis da respectiva práxis, na qual esse profissional é simultaneamente: "(a) um profissional que domina um instrumental próprio de trabalho e sabe fazer uso dele; (b) um pensador capaz de ressignificar criticamente sua prática e as representações sociais sobre seu campo de atuação; (c) um cidadão que faz parte de uma sociedade e de uma comunidade" (SEE-MG, 2001 apud COELHO, op. cit.). Nesse sentido, podemos concordar com Lawn (op.cit. 118-119) que a identidade é "produzida" através de um discurso que, simultaneamente, explica e constrói o sistema. Dessa forma, a identidade do professor simboliza o sistema e a nação que o criou. Reflete a "comunidade imaginada" da nação, em momentos em que esta é crucial para o estabelecimento ou reformulação dos seus objetivos econômicos ou sociais, tal como se encontram definidos pelo Estado.

\section{Na ordem da violência do discurso e da identidade: a teoria da reprodução}

Supomos, com Michel Foucault (2008, p. 8), que em toda sociedade a produção do discurso é ao mesmo tempo controlada, selecionada, organizada e redistribuída por um certo número de procedimentos cuja função é conjurar os poderes e perigos discursivos para dominar seu acontecimento aleatório e esquivar sua pesada materialidade. Neste processo, supomos também, desta vez com Bourdieu e Passeron (2008), que na escola, os discursos tendem a assegurar-se do monopólio da violência simbólica legítima, se nós partirmos do axioma zero da teoria da reprodução que afirma

Todo poder de violência simbólica, isto é, todo poder que chega a impor significações e a impô-la como legítimas, dissimulando as relações de força que estão na base de sua força, acrescenta sua própria força, isto é, propriamente simbólica, a essas relações de força (BOURDIEU; PASSERON, 2008, p. 25).

Dessa forma, podemos supor que os PCN2-EF2 veiculam um discurso permeado pela violência simbólica porque impõe significações ao espaço escolar, ao dissimular as relações de força entre os sujeitos aí localizados em posições. Na realidade, tal discurso tenta reorganizar algo que está em crise em razão do conhecimento não está mais 
centrado no ambiente escolar; a era da informação vem obrigando os governos a reorganizar os sentidos desse espaço estratégico cujos sentidos de ser é promover suas ações governamentais que chamamos política, reproduzindo as relações sociais de poder.

Essa violência simbólica e sistêmica porque segue uma hierarquia, estruturada em um jogo de linguagem que vai afetando os sujeitos assujeitados pelos discursos situados nas relações de força dentro do mundo social, onde ordena quem tem poder e obedece quem está na posição de cumprir ordens. No dizer de Saviani (1985, p.21), este axioma (proposição zero), que enuncia a teoria geral da violência simbólica, se aplica ao sistema do ensino que é definido, pois, como uma modalidade específica de violência simbólica [...]. Eis aqui o nosso interesse por esta teoria.

De acordo com Vasconcellos (2002, p. 80), através do uso da noção de violência simbólica, Pierre Bourdieu ${ }^{4}$ tenta desvendar o mecanismo que faz com que os indivíduos vejam como "naturais" as representações ou as ideias sociais dominantes. A violência simbólica é desenvolvida pelas instituições e pelos agentes que as animam e sobre a qual se apóia o exercício da autoridade. É nessa perspectiva que vemos os PCN2-EF2, analisados anteriormente como corpus de nossa pesquisa de cunho interpretativo, ou seja, as questões que Bourdieu nos traz, e, aqui nosso interesse é pela violência simbólica, como assinalamos antes, nos permite identificar a imposição de significações da política linguística aqui em análise não só aos professores, mas também aos alunos.

De acordo com Wacquant (2002, p. 98),

\begin{abstract}
"Bourdieu cunhou a noção de capital cultural e inseriu-o em uma concepção generalizada de capital como 'energia social' congelada e conversível. Ele recuperou e retrabalhou o conceito aristotélicotomista de habitus para elaborar uma filosofia disposicional da ação como propulsora dos socialmente constituídos e individualmente incorporados "esquemas de percepção e apreciação".
\end{abstract}

Grosso modo, o conceito de capital cultural (diplomas, nível de conhecimento geral, boas maneiras) é utilizado para se distinguir do capital econômico e do capital social (rede de relações sociais), i.e., na educação se acumula o capital cultural na forma de conhecimentos, de livros, dos diplomas obtidos etc. Já o conceito de habitus, dito por

\footnotetext{
${ }^{4}$ Aqui a autora refere-se apenas a Pierre Bourdieu, embora a obra em que aparece a teoria da violência simbólica seja assinada também por Jean-Claude Passeron, talvez pelo fato do artigo ter sido escrito como uma forma de homenagear o sociólogo francês na ocasião do seu falecimento em 2002.
} 
Bourdieu (2007, p. 61), "como indica a palavra, é um conhecimento adquirido e também um haver, um capital (de um sujeito transcendental na tradição idealista) o habitus, a hexis, indica a disposição incorporada, quase postural". Dito de outra forma, o conceito de habitus que Bourdieu desenvolveu ao longo da sua obra corresponde a uma matriz, determinada pela posição social do indivíduo que lhe permite pensar, ver e agir nas mais variadas situações. "O habitus traduz, dessa forma, estilos de vida, julgamentos políticos, morais, estéticos, sendo também um meio de ação que permite criar ou desenvolver estratégias individuais ou coletivas" (VASCONCELLOS, op . cit., p. 79). Assim, em síntese, a noção de habitus exprime, sobretudo, a recusa a toda uma série de alternativas nas quais a ciência social se encerrou, a da consciência (ou do sujeito) e do inconsciente, a do finalismo e do mecanismo etc.

De que forma estes conceitos podem ser articulados em nossa análise discursivo-desconstrutiva? Como dissemos antes, o discurso analisado é permeado pela violência simbólica, pois impõe significações aos professores quanto ao seu posicionamento na escola e o seu papel político de agente executor das ações necessárias para o cumprimento da lei que assegura uma escola voltada para o exercício da cidadania. Tal discurso tem o formato de um capital cultural porque contém em si o discurso de especialistas e está destinado a circular no ambiente escolar por meio de práticas discursivas que reforçam sua legitimidade. Dessa forma, veiculado pelo sistema de ensino, contribui para a reprodução das relações sociais, dissimulando sob aparências da neutralidade, o comprimento desta função, No dizer de Bourdieu (2005, p. 311),

\begin{abstract}
ao converter hierarquias sociais em hierarquias escolares, o sistema educacional cumpre uma função de legitimação cada vez mais necessária à perpetuação da "ordem social" uma vez que a evolução das relações de força entre as classes tende a excluir de modo mais completo a imposição de uma hierarquia fundada na afirmação bruta e brutal das relações de força.
\end{abstract}

Esta reconfiguração da escola e do professor tem senão o papel de atualização dos discursos e manutenção do poder do Estado sobre a escola, seu aparelho ideológico por excelência, frente às demandas do mundo globalizado, cujas ações interferem na política local de forma a assegurar a emergência do mercado global. Vale à pena lembrar que é a primeira fez na história da humanidade que tal um conjunto de técnicas envolve o planeta como um todo e faz sentir, instantaneamente, sua presença (SANTOS, 2008, p. 25). O nosso PCN2-EF2 é ao mesmo tempo parte da política 
econômica global, da política linguística, da política educacional curricular. Neste último caso, pensamos com Silva (1995, p. 200) que o currículo é um dos locais privilegiados onde se entrecruzam saber e poder, representação e domínio, discurso e regulamentação. Como política linguística, o documento está inserido nas ações de mercantilização das línguas, das quais o português se inclui. Todas estas políticas estão ligadas ao processo de globalizar os mercados. "O mundo torna-se unificado em virtude das novas condições técnicas, bases sólidas para uma ação humana mundializada" (SANTOS, op.cit.).

Estes eventos globais acabam impondo mudanças nas relações sociais e nos habitus. E a escola continua sendo a porta para as mudanças. No caso inglês, analisado por Lawn (2001, p. 130), “os professores transformaram-se numa 'massa' de empregados de organizações pseudo-privadas, homogeneizadas por este processo, ao mesmo tempo que, pela competição entre elas, se diferenciam". No nosso caso, ainda estamos contabilizando tais efeitos. Para Souza (2003, p. 344), “diante da impossibilidade de alcançar a complexidade de conceitos desconhecidos, o professor experimenta uma espécie de sensação de culpa que o remete ao lugar da incompetência, porque ele não consegue compreender os PCNs (sic) nem colocá-los em prática na sala de aula".

\section{Considerações finais (ou em desconstrução)}

O discurso aqui analisado se apresenta como uma necessidade porque falta algo, a referência comum curricular nacional e justifica-se ao usar como principal argumento os baixos níveis da escola básica no Brasil com índices inaceitáveis mesmo em países muito mais pobres. Dentre os entraves para o sucesso escolar, está a evasão e a exclusão. Do ponto de vista político, entraves que impedem a igualdade social e, consequentemente, o exercício da cidadania na democracia brasileira, por isso a ação política do governo que convida especialistas para ajudar a mudar esse quadro. Mas para criar tal referência é preciso mexer nos sentidos da estrutura escolar com novas identidades para o sujeito-aluno e o sujeito-professor. Para delimitar o assunto, aqui optamos pela identidade do último, cujo peso das responsabilidades é maior. Em suma, a tessitura da rede discursiva se constrói a partir de: 
a) Uma necessidade (cujo não-dito é a "falta" que faz surgir tal necessidade) que instaura verdades (o discurso instaura novas verdades de uma política para os tempos democráticos)

b) As verdades se constituem a partir da relação Política- democracia- cidadania autonomia contra políticas autoritárias que criam dependência.

c) A língua, como fio condutor de verdade, passa a ser vista como meio para gerar a igualdade social, sendo reificada.

d) Os sujeitos são professores e alunos, ligados pelo objeto do conhecimento linguísticos, cada um posicionados no espaço institucional escolar para que o exercício da cidadania possa acontecer nas ações linguísticas mediadas pelo professor.

Por meio de sequência discursiva referencial (sdr) e de paráfrases, a trama do discurso vai aos poucos compondo uma nova identidade para o professor de português como L1. Vimos que por meio dos PCN2-EF2, a política linguística confere plenos poderes à língua, cujo agente privilegiado, para sua execução, é o professor, investido de responsabilidade política e linguística.

Nestes tempos, a Pós-modernidade parece estar pondo em xeque os sentidos concebidos na e para a Modernidade, um deles é o da identidade. Qual o sentido dela hoje? Como vimos, ela ainda constitui um instrumento nas mãos dos governos dos Estados, dito modernos. O nosso papel aqui foi transitar pela fronteira entre o que é politicamente dizível ou indizível, do pensável e do impensável como nos lembra Bourdieu (2007, p.165), uma vez que, no dizer de Foucault (1996, p. 44), "todo sistema de educação é uma maneira de política de manter ou de modificar a apropriação dos discursos, com os saberes e os poderes que eles trazem consigo".

Nessa perspectiva, partimos para analisar o discurso dos PCN2-FE de língua portuguesa, publicado em 1998. A ordem deste discurso procura inculcar tal identidade. Mas uma identidade como esta demanda condições de trabalho que não existe na realidade da maioria das escolas brasileiras. Tal desencontro promove a violência simbólica por diversas razões: uma delas é a dificuldade que os professores encontram frente às novas exigências, a outra é ser culpado pelo fracasso escolar. Assim, enquanto o sistema educativo não souber como favorecer a adoção de idéias novas sem impô-las pela burocracia, as crises e o fracasso vão estar presentes no nosso cotidiano escolar. Não podemos nos esquecer que estamos andando nos territórios da Linguagem. Territórios cheios de encruzilhadas onde os sentidos são construídos por/para sujeitos. Como um phármakon, ela é ao mesmo tempo remédio e veneno que tomamos ou que oferecemos ao outro numa espécie de jogo. Como discurso, ela pode ser usada na construção de políticas linguísticas, como é o caso dos PCN2-EF2, os quais instauram 
um processo de identificação numa rede de conceitos e procedimentos que aparecem como positivos com os quais os professores devem se identificar, ou melhor, "um lugar idealizado de referência para o professor 'atualizado"” (SOUZA, 2003, p. 337). Não podemos nos esquecer que esta política faz parte de uma onda maior cujo vento da mundialização vai movimentando os Estados e seus governos.

\section{REFERÊNCIAS}

APPLE, M. W. O conhecimento oficial. Petrópolis, RJ: Vozes, 1997.

APPLE, M. W. Ideologia e currículo. Tradução Vinicius Figueira. $3^{\text {a }}$ ed. Porto Alegre: Artmed, 2006

ARMENGAUD, F. A pragmática. Tradução de Marcos Marcionilo. - São Paulo: Parábola Editorial, 2006.

BOURDIEU, P. A economia das trocas simbólicas. Tradução de Sergio Miceli, Silvia de Almeida Prado, Sonia Miceli e Wilson Campos Vieira. - $6^{a}$ ed. - São Paulo: Perspectiva, 2005

BOURDIEU, P.; PASSERON, J-C. A Reprodução: elementos para uma teoria do sistema de ensino. - Petrópolis, RJ: Vozes, 2008.

BRASIL. Secretaria de Educação Fundamental. Parâmetros curriculares nacionais: terceiro e quarto ciclos do ensino fundamental: língua portuguesa. - Brasília:

MEC/SEF, 1998.

CALVET, L. As políticas linguísticas. Tradução de Isabel de Oliveira Duarte, Jonas Tenfen e Marcos Bagno. - São Paulo: Parábola Editorial, 2007.

CARVALHO, C. Políticas educacionais no contexto de mudanças na esfera pública. In: BAUER, C. et al. Políticas Educacionais e discursos pedagógicos. - Brasília: Líber Livro Editora, 2007.

CHARAUDEAU, P. Linguagem e discurso: modos de organização. Coordenação da equipe de tradução Angela M. S. Correia e Ida Lúcia Machado. - São Paulo: Contexto, 2008.

COELHO, M. I de M. Formação e construção de identidade de professores e a cultura de gerencialismo e performatividade do estado. Disponível em <http://www.isecure.com.br/anpae/297.pdf. $>$. Acesso em: maio de 2009.

CORACINI, M. J. O discurso da lingüística aplicada e a questão da identidade: entre a modernidade e a pós-modernidade. In: BERTOLD, E. S. \& CORACINI, M. J. (Orgs.) O desejo da teoria e a contingência da prática: discursos sobre nna sala de aula. Campinas, SP: Mercado de Letras, 2003a. 
COURTINE, J. J. Analyse du discours politique : le discours commnuniste adressé aux chrétiens. Langages, Paris, n. 62, p. 9-128, 1981.

COURTINE, J. J. O olhar da ciência e a construção da identidade do professor de línguas. In: BERTOLD, E. S. \& COURTINE, J. J (Orgs.) O desejo da teoria e a contingência da prática: discursos sobrelna sala de aula. - Campinas, SP: Mercado de Letras, 2003a.

COURTINE, J. J. Subjetividade e identidade do (a) professor (a) de português. In: COURTINE, J. J. (Org.). identidade e discurso: (des) construindo subjetividades. Campinas, SP: Editora da UNICAMP; Chapecó: Argos Editora Universitária, $2003 b$.

DEMO, P. A nova LDB: ranços e avanços. - $21^{\text {a }}$ edição -. Campinas-SP: Papirus, 2008.

FOUCAULT, M. A ordem do discurso: aula inaugural no Collège de France.

Tradução de Laura Fraga de Almeida Sampaio. -São Paulo, Edições Loyola, 2008.

GERALDI, J. W. Abordagem sócio-interacionista no ensino, leitura e escrita. Revista de Educação AEC- no 101/1996.

LAWN, M. Os Professores e a Fabricação de Identidades. In: Currículo sem Fronteiras, v.1, n.2, p. 117-130, Jul/Dez 2001

MAINGUENEAU, D. Novas tendências em análise do discurso. - $3^{\mathrm{a}}$ ed. - Campinas, SP: Pontes: Editora da Universidade Estadual de Campinas. 1997.

MAINGUENEAU, D. Gênese dos discursos. Tradução de Sírio Possenti. - Curitiba: Criar, 2007.

NIETZSCHE, F. Sobre a verdade e mentira no sentido extra-moral. In: Obras incompletas, vol. I; tradução de Rubens Rodrigues Torres Filho. - São Paulo: Nova cultural, 1987.

ORLANDI, E. L. P. Identidade lingüística escolar. In: SIGNORINI (org.) Língua(gem) e identidade - Campinas-SP: Mercado de Letras, 1998.

ORLANDI, E. L. P. A linguagem e seu funcionamento: as formas do discurso. $-4^{\mathrm{a}}$ edição, $3^{\text {a }}$ reimpressão - Campinas, SP: Pontes, 2003.

RAJAGOPALAN, K. Por uma linguística crítica: linguagem, identidade e a questão ética. - São Paulo: Parábola Editorial, 2001.

RODRÍGUEZ, M. V. Globalização das políticas públicas: impactos das reformas educacionais nos anos de 1990. In: LOMBARDI, J. C. (org.) Globalização, pósmodernidade e educação: história, filosofia e temas transversais. - 2 ed. rev. e ampl. Campinas, SP: Autores Associados; Caçador, SC: UNC, 2003.

ORLANDI, E. L. P. Modos de transposição dos PCNS às práticas de sala de aula: progressão curricular e projetos. In: ORLANDI, E. L. P. (Org.) A prática de linguagem em sala de aula: praticando os PCNS. - Campinas, SP: Mercado de Letras, 2000 . 
SANTOS, M. Por uma outra globalização: do pensamento único à consciência universal. - 17ª edição -. Rio de Janeiro: Record, 2008.

SARUP, M. Alienação e ensino. In SARUP, M. Marxismo e educação: abordagem fenomenológica e marxista da educação. Tradução de Waltensir Dutra. - Rio de Janeiro: Guanabara, 1986.

SIGNORINI, I. Metapragmáticas da língua em uso: unidades e níveis de análise In: SIGNORINI, I. (org.) Situar a língua(gem). - São Paulo: Parábola, 2008.

SOARES, M. B. Português na escola: história de uma disciplina. Revista de Educação AEC- n' 101/1996.

SOUZA, D. M. Identidade transversal e política de verdades: políticas curriculares e a construção da identidade do professor de línguas estrangeiras. In: CORACINI, M. J. (Org.) Identidade e discurso: (des) construindo subjetividades. - Campinas, SP: Editora da UNICAMP; Chapecó: Argos Editora Universitária, 2003.

SUASSUNA, L. O que são, por que e como se escreveram os parâmetros curriculares nacionais de língua portuguesa - o professor como leitor de propostas oficiais de ensino. In: SILVA, C. S. R. da \& MARINHO, M. (Orgs.) Leituras do professor. Campinas, SP: Mercado de Letras: Associação de Leitura do Brasil - ALB, 1998.

VIEIRA, S. L. Políticas de formação em cenário de reforma. In: AMARAL, A. L.; VEIGA, I. P. A. (Orgs.). Formação de professores: políticas e debates. - Campinas, SP: Papirus, 2002.

VASCONCELLOS, M. D. Pierre Bourdieu: a herança sociológica. In: Educação \& Sociedade, ano XXIII, no 78, Abril/2002.

WACQUANT, L. J. D. O legado sociológico de Pierre Bourdieu: duas dimensões e uma nota pessoal. Tradução de Adriano Nervo Codato e Gustavo Biscaia de Lacerda. In:

Rev. Sociol. Polít., Curitiba, 19, p. 95-110, nov. 2002.

WOODWARD, K. Identidade e diferença: uma introdução teórica e conceitual. In: SILVA, T. T. (org.). Identidade e diferença: a perspectiva dos estudos culturais. Petrópolis: Vozes, 2008.

\section{Como referenciar este artigo}

ARAÚJO, Alex Pereira de. A desconstrução da política linguística educacional: em foco a identidade do professor de português. Revista Ibero-Americana de Estudos em Educação, Araraquara/SP, v. 11, n. 3, p.1259-1280, 2016. Disponível em: <https://dx.doi.org/10.21723/riaee.v11.n3.2827>. E-ISSN: 1982-5587.

Submetido em: 26/08/2015

Aprovação final em: 28/07/2016 